\title{
Avaliação da Soldagem Multipasse de Chapas Espessas de Aços Inoxidáveis Lean Duplex UNS S32304 Soldadas pelos Processos SMAW, GMAW e FCAW - Parte II: Resistência à Corrosão
}

\author{
(Evaluation of multipass welding of thick lean duplex stainless steel UNS S32304 plates welded by SMAW, GMAW and FCAW \\ - Part II - Corrosion Resistance)
}

\begin{abstract}
Carla Soares Souza ${ }^{1}$,Vanessa de Freitas Cunha Lins², Dalila Moreira da Silveira², Cintia Gonçalves Fonseca Costa ${ }^{2}$, Ronaldo Cardoso Junior ${ }^{3}$, Frederico Rodrigues Campos 4 , Alexandre Queiroz Bracarense ${ }^{4}$

${ }^{1}$ Fiat Automóveis S.A., Centro de Tecnologia em Ciência dos Materiais, Belo Horizonte, Minas Gerais, Brasil, carla.souza@fiat. com.br,; ${ }^{2}$ Universidade Federal de Minas Gerais, Departamento de Engenharia Química/Laboratório de Corrosão e Engenharia de Superficie, Belo Horizonte, Minas Gerais, Brasil,vlins@deq.ufmg.br; ${ }^{3}$ ESAB Indústria e Comércio LTDA, Centro de Processos, Contagem, Minas Gerais, Brasli; ${ }^{4}$ Universidade Federal de Minas Gerais, Departamento de Engenharia Mecânica/ Laboratório de Simulação e Soldagem, Belo Horizonte, Minas Gerais, Brasil
\end{abstract}

\section{Resumo}

Os aços inoxidáveis duplex (AID) vêm se apresentando como uma excelente alternativa para aplicações em que alta resistência à corrosão e alta resistência mecânica são requeridas. Contudo, os AID, incluindo os aços inoxidáveis lean duplex, apresentam soldabilidade inferior em relação aos aços inoxidáveis austeníticos. Esse trabalho tem como objetivo a avaliação da resistência à corrosão de juntas soldadas multipasse de chapas de $22 \mathrm{~mm}$ de espessura da liga inoxidável lean duplex UNS S32304, utilizandose os processos SMAW, GMAW e FCAW e consumiveis com dois tipos de composição química, 22\%Cr9\%Ni3\%Mo e 23\%Cr7\% Ni, totalizando seis experimentos. As juntas soldadas foram analisadas usando-se a técnica de polarização anódica potenciodinâmica para determinação do potencial de pite do material. O eletrólito estudado foi uma solução salina de cloreto de sódio 3,5\% $\mathrm{m} / \mathrm{v}$. A junta de aço lean duplex soldada pelo processo GMAW com o consumivel $22 \% \mathrm{Cr} 9 \% \mathrm{Ni3} \% \mathrm{Mo}$ apresentou o melhor comportamento frente à corrosão no meio salino. A região da raiz da solda apresentou o maior potencial de pite em relação ao topo das juntas soldadas. As juntas de aço lean duplex soldadas usando-se o processo FCAW apresentaram um comportamento característico de corrosão generalizada no meio de solução salina, ao contrário das demais amostras.

Palavras-chave: Lean duplex, Soldagem Multipasse, Corrosão, Polarização potenciodinâmica

\begin{abstract}
Duplex stainless steels (DSS's) have been placed as an excellent alternative for applications where high corrosion resistance and high mechanical strength are required. However, the DSS's, including the lean duplex stainless steels, present lower weldability than the austenitic stainless steels. This study aims to evaluate the corrosion resistance of welded joints using multipass welding of lean duplex stainless alloy UNS S32304 plates $22 \mathrm{~mm}$ thick, using the SMAW, GMAW and FCAW consumables with two types of chemical composition, $22 \% \mathrm{Cr} 9 \% \mathrm{Ni} 3 \% \mathrm{Mo}$ and $23 \% \mathrm{Cr} 7 \% \mathrm{Ni}$, giving a total of six experiments. The welded joints were evaluated using the anodic potentiodynamic polarization technique to determine the pitting potential of the material. The electrolyte studied was $3.5 \% \mathrm{w} / \mathrm{v}$ sodium chloride aqueous solution. The lean duplex steel welded by GMAW process with consumable with $22 \% \mathrm{Cr} 9 \%$ Ni3\%Mo showed the best behavior against corrosion in saline solution. The root of the weld region had the highest pitting potential compared to the top of the welded joints. The lean duplex steel joints welded using FCAW process showed a behavior characteristic of general corrosion in the medium of saline solution, unlike the other samples.
\end{abstract}

Key-words: Lean duplex, Multipass Welding, Corrosion, Potentiodynamic Polarization

\section{Introdução}

Os aços inoxidáveis duplex são utilizados industrialmente devido à sua resistência à corrosão em ambientes encontrados nas operações onshore e offshore e à sua alta resistência mecânica [1]. Aplicações típicas para esses tipos de aço são tubos

Recebido em 19/06/2012. Texto Final em 05/04/2013. coletores submarinos, flowlines ou tubos condutores, redes de tubos submarinas e sistemas de processamento topside. Os aços duplex têm sido também amplamente utilizados em muitas áreas além da petroquímica, como na indústria de papel e celulose.

No entanto, devido ao teor de níquel $(5 \%$ - $7 \%$ ) e molibdênio (cerca de $3 \%$ ) requerido em sua composição, o aço inoxidável duplex tem um alto custo de produção e por apresentar uma solidificação iniciada como ferrita, a soldabilidade dos aços duplex é inferior à dos aços austeníticos, sendo necessário um controle rigoroso de composição química e ciclo térmico de soldagem. 
Assim, em pesquisas mais recentes foi desenvolvido o aço inoxidável lean duplex (AILD). Este aço apesar de ainda apresentar dificuldade na soldagem por causa da composição química, apresenta o atrativo de ser mais barato que o duplex convencional devido à substituição parcial do níquel por manganês e nitrogênio. Os AILD apresentam como composição química típica $20-24 \%$ de cromo, $1-5 \%$ de níquel, $0,1-0,3 \%$ de molibdênio e $0,10-0,22 \%$ de nitrogênio [1]. O lean duplex mais comum é a liga UNS S32304 que apresenta composição nominal de $23 \%$ de cromo, $4 \%$ de níquel, adições de molibdênio de até $0,6 \%$, nitrogênio e manganês.

Em comparação com os aços austeníticos como o AISI 304L e 316L, os aços lean duplex apresentam a vantagem de ter limites de escoamento entre 430 e $450 \mathrm{MPa}$, o que é quase o dobro dos valores dos limites dos austeníticos, e com isso possibilitam grandes economias na espessura de paredes de tubos.

O estudo da corrosão deste material propicia o direcionamento de sua aplicação e minimiza os custos associados à corrosão nos diversos equipamentos em que vem sendo aplicado. A literatura acerca da corrosão de aços lean duplex ainda é escassa e aborda temas como o efeito do envelhecimento na resistência à corrosão de aços lean duplex 2101 [2], o papel do molibdênio na corrosão por pite de armadura de aço lean duplex em concreto [3] e análise da corrosão de aços lean duplex $2101 \mathrm{em}$ meio salino usando a técnica de ruído eletroquímico [4]. Estudos da camada passiva de aços lean duplex são relatados na literatura $[5,6]$. A formação de óxidos no processo de soldagem exerce uma forte influência na resistência à corrosão dos aços inoxidáveis lean duplex e o mecanismo envolvido ainda não foi completamente elucidado [1,7].

A corrosão localizada é um dos fenômenos mais importantes dos AID, responsável por sua degradação num determinado meio [3,4]. O parâmetro PREN (Pitting Resistance Equivalent Number) é geralmente aceito como uma estimativa da resistência à corrosão localizada dos aços inoxidáveis duplex, sendo definido pela Equação (1) que será usada neste trabalho.

PREN $=1 .(\% \mathrm{Cr})+3,3 .(\% \mathrm{Mo})+16 .(\% \mathrm{~N})$

Eq. 1

Todos os processos de soldagem por fusão podem ser utilizados, desde que procedimentos de soldagem adequados sejam seguidos. Na Parte I deste trabalho [8], o objetivo foi avaliar a soldabilidade da liga de aço inoxidável lean duplex UNS S32304 buscando o processo de soldagem, consumível e procedimento mais eficaz do ponto de vista de produtividade, metalúrgico e mecânico. Levando-se em consideração os aspectos práticos, chapas espessas de $22 \mathrm{~mm}$ foram empregadas e unidas através de soldagem multipasse utilizando-se três processos de soldagem distintos (SMAW, GMAW e FCAW) e consumíveis de composição química do tipo $22 \% \mathrm{Cr} 9 \% \mathrm{Ni}$ (com adição de molibdênio) e $23 \% \mathrm{Cr} 7 \% \mathrm{Ni}$ (sem adição de molibdênio). $\mathrm{O}$ ensaio de microdureza mostrou menor dureza no metal de base próximo a raiz da solda, região reaquecida pelos demais passes, enquanto que a maior dureza foi observada na superfície da zona fundida [8]. A energia absorvida no impacto, avaliada pelo ensaio Charpy, foi menor para as juntas soldadas pelo processo SMAW [8].
O objetivo geral da pesquisa é fornecer as informações necessárias ao mercado sobre a soldagem dos aços inoxidáveis lean duplex UNS S32304. Na primeira parte foram avaliadas as propriedades mecânicas como a microdureza e tenacidade [8]. Nesta parte, foi avaliada a resistência à corrosão de juntas soldadas por diferentes processos, SMAW, GMAW e FCAW usando-se a técnica de polarização anódica potenciodinâmica para determinação do potencial de pite do aço e avaliação de seu comportamento frente à corrosão em meio salino.

\section{Materiais e Métodos}

Esta pesquisa é uma continuação do trabalho realizado por Cardoso Junior [8], que avaliou o comportamento mecânico e metalúrgico de chapas espessas do aço inoxidável lean duplex UNS S32304, soldadas pelos processos SMAW, GMAW e FCAW. Nesta parte, avaliou-se a resistência à corrosão em meio de solução salina, usando a técnica de polarização anódica potenciodinâmica, das amostras obtidas analisadas em duas diferentes regiões da solda (Raiz e Topo). Cada condição de análise foi avaliada em duplicata.

Foram soldados seis corpos de prova com $350 \times 180 \times 22$ $\mathrm{mm}$, utilizando-se três processos de soldagem distintos (SMAW, GMAW e FCAW) e consumíveis com dois tipos de composição química, $23 \% \mathrm{Cr} 7 \% \mathrm{Ni}$ (sem molibdênio) e $22 \% \mathrm{Cr} 9 \% \mathrm{Ni} 3 \% \mathrm{Mo}$ (com molibdênio), conforme Tabela 1 [8].

O metal de base utilizado foi o UNS S32304 fornecido pela Aperam South America cuja composição química e propriedades mecânicas são apresentadas na Tabela 2 [8]. A Tabela 3 apresenta a composição química e propriedades mecânicas dos consumíveis de soldagem, sendo que as mesmas foram realizadas através de enchimentos, seguindo a norma ASME II Part C. Todos os consumíveis foram fornecidos pela ESAB Indústria e Comércio LTDA.

As juntas foram preparadas com chanfro em $\mathrm{V}$ com ângulo $60^{\circ}$, nariz de $1 \mathrm{~mm}$ e abertura de $4 \mathrm{~mm}$. Realizou-se soldagem unilateral, sendo que para todos os ensaios foram empregados suportes cerâmicos de perfil retangular com $13 \mathrm{~mm}$ de abertura e $1,3 \mathrm{~mm}$ de profundidade, os quais dispõem de uma fita metálica auto-adesiva de alumínio para fixação [8].

Dessa maneira, em todos os seis ensaios realizados foram produzidas três regiões distintas na zona fundida: a raiz, o enchimento e o acabamento. Na primeira, ao contrário do procedimento normalmente utilizado para soldagem dos AID, não se utilizou gás de purga, pois se lançou mão do suporte cerâmico e soldagem manual [8]. Entretanto, para os demais passes empregou-se o trator de soldagem ESAB Railtrac FW1000, de forma a garantir maior homogeneidade dos parâmetros, exceto para o processo SMAW em que toda a soldagem foi manual [8].

A energia líquida de soldagem (HL) de 1,3 kJ.mm-1 foi escolhida com base em testes prévios, em que a zona termicamente afetada (ZTA) foi simulada através da soldagem autógena pelo processo GTAW e, em seguida, foi determinada a proporção austenita/ferrita. Os testes prévios para determinação do aporte térmico ideal para soldagem do AILD UNS S32304 não serão detalhados nesse artigo [8]. 
Tabela 1. Processos, consumíveis e gases de proteção testados [8].

\begin{tabular}{|c|c|c|c|c|c|}
\hline Teste & Processo & Tipo & Especificação EN & Diâmetro (mm) & Gás de Proteção \\
\hline SMAW2307 & SMAW & $23 \% \mathrm{Cr} 7 \% \mathrm{Ni}$ & E Z 237 N L R & 3,25 & N.A. \\
\hline SMAW2209 & SMAW & $22 \% \mathrm{Cr} 9 \% \mathrm{Ni} 3 \% \mathrm{Mo}$ & E 2293 N L R 32 & 4,00 & N.A. \\
\hline GMAW2307 & GMAW & $23 \% \mathrm{Cr} 7 \% \mathrm{Ni}$ & G $237 \mathrm{NL}$ & 1,00 & Star GoldTM SS \\
\hline GMAW2209 & GMAW & $22 \% \mathrm{Cr} 9 \% \mathrm{Ni3} \% \mathrm{Mo}$ & G $2293 \mathrm{NL}$ & 1,00 & Star GoldTM SS \\
\hline FCAW2307 & FCAW & $23 \% \mathrm{Cr} 7 \% \mathrm{Ni}$ & T 237 N L P & 1,20 & $75 \% \mathrm{Ar}+25 \% \mathrm{CO} 2$ \\
\hline FCAW2209 & FCAW & $22 \% \mathrm{Cr} 9 \% \mathrm{Ni3} \% \mathrm{Mo}$ & T 2293 N L P & 1,20 & $75 \% \mathrm{Ar}+25 \% \mathrm{CO} 2$ \\
\hline
\end{tabular}

Nota: N.A.: Não se aplica; Star Gold SS: Mistura ternária 95\%Ar+3\%CO2+2\%N2 fornecida pela Praxair.

Tabela 2. Composição química, em \%, e propriedades mecânicas do metal de base utilizado [8].

\begin{tabular}{|c|c|c|c|c|c|c|c|c|c|c|c|c|c|c|}
\hline $\mathrm{C}$ & $\mathrm{Mn}$ & $\mathrm{Si}$ & $\mathrm{P}$ & $\mathrm{S}$ & $\mathrm{Cr}$ & $\mathrm{Ni}$ & $\mathrm{Mo}$ & $\mathrm{Cu}$ & $\mathrm{N}$ & $\mathrm{O}$ & PREN & $\begin{array}{c}\text { L.R. } \\
(\mathrm{MPa})\end{array}$ & $\begin{array}{c}\text { L.E. } \\
(\mathrm{Mpa})\end{array}$ & $\begin{array}{c}\mathrm{A} \\
(\%)\end{array}$ \\
\hline 0,019 & 1,35 & 0,39 & 0,0282 & 0,0004 & 22,45 & 3,63 & 0,44 & 0,5 & 0,1128 & 0,0033 & 25,7 & 670 & 520 & 38 \\
\hline
\end{tabular}

Nota: L.R.=Limite de resistência; L.E.=Limite de escoamento; A=Alongamento.

Tabela 3. Composição química, em \%, e propriedades mecânicas dos metais de solda [8].

\begin{tabular}{|c|c|c|c|c|c|c|c|c|c|c|c|c|c|c|}
\hline Consumível & $\mathrm{C}$ & $\mathrm{Mn}$ & $\mathrm{Si}$ & $\mathrm{P}$ & $\mathrm{S}$ & $\mathrm{Cr}$ & $\mathrm{Ni}$ & $\mathrm{Mo}$ & $\mathrm{Cu}$ & $\mathrm{N}$ & $\mathrm{PREN}$ & $\begin{array}{c}\text { L.R. } \\
(\mathrm{MPa})\end{array}$ & $\begin{array}{c}\text { L.E. } \\
(\mathrm{MPa})\end{array}$ & $\begin{array}{c}\mathrm{A} \\
(\%)\end{array}$ \\
\hline SMAW2307 & 0,028 & 0,78 & 0,96 & 0,017 & 0,014 & 22,60 & 7,62 & 0,36 & 0,26 & 0,13 & 26,0 & 754 & 609 & 26 \\
\hline SMAW2209 & 0,027 & 0,79 & 0,99 & 0,019 & 0,012 & 21,92 & 9,31 & 3,15 & 0,06 & 0,12 & 34,6 & 857 & 691 & 25 \\
\hline GMAW2307 & 0,03 & 0,88 & 0,86 & 0,017 & 0,01 & 23,82 & 8,92 & 0,31 & 0,095 & 0,13 & 26,9 & 730 & 560 & 32 \\
\hline GMAW2209 & 0,029 & 1,47 & 0,57 & 0,02 & 0,009 & 21,94 & 9,20 & 3,12 & 0,14 & 0,14 & 34,5 & 765 & 600 & 28 \\
\hline FCAW2307 & 0,024 & 0,92 & 0,96 & 0,018 & 0,011 & 23,7 & 8,93 & 0,3 & 0,095 & 0,12 & 26,6 & 774 & 626 & 33 \\
\hline FCAW2209 & 0,022 & 1,06 & 0,91 & 0,022 & 0,013 & 21,66 & 9,2 & 2,94 & 0,18 & 0,15 & 33,8 & 828 & 637 & 26 \\
\hline
\end{tabular}

Nota: Para GMAW e FCAW foram usados os gases da Tabela 1. Enchimentos realizados segundo ASME II Part C. L.R.=Limite de resistência; L.E.=Limite de escoamento; A=Alongamento.

Tabela 4. Parâmetros de soldagem reais para os passes de raiz e médios para os demais passes [8].

\begin{tabular}{|ccccccc|}
\hline \multirow{2}{*}{ Ensaio } & Passes & Corrente $(\mathrm{A})$ & Tensão $(\mathrm{V})$ & Velocidade $(\mathrm{cm} / \mathrm{min})$ & $\mathrm{H}(\mathrm{kJ} / \mathrm{mm})$ & Interpasse $\left({ }^{\circ} \mathrm{C}\right)$ \\
& Raiz & 85 & 25,0 & 11,3 & 1,13 & N.A. \\
SMAW2307 & Demais & 135 & 31,1 & 14,8 & 1,70 & $100-150$ \\
& Raiz & 140 & 29,0 & 12,1 & 2,01 & N.A. \\
SMAW2209 & Demais & 160 & 28,7 & 15,9 & 1,73 & $100-150$ \\
& Raiz & 210 & 29,0 & 13,6 & 2,69 & N.A. \\
GMAW2307 & Demais & 213 & 29,0 & 23,1 & 1,60 & $100-150$ \\
& Raiz & 195 & 29,0 & 15,3 & 1,58 & 1,21 \\
GMAW2209 & Demais & 212 & 29,0 & 23,3 & 1,56 & $1,50-150$ \\
& Raiz & 208 & 29,0 & 23,2 & 1,58 & $100-150$ \\
FCAW2307 & Demais & 210 & 29,0 & 23,2 & 1,59 & N.A. \\
& Raiz & 210 & 29,0 & 23,3 & 22,9 & $100-150$ \\
\hline
\end{tabular}

N.A.: Não se aplica. Não foi realizado pré-aquecimento em nenhumas das situações. 
Admitindo-se o rendimento térmico $(\eta)$ dos processos SMAW, GMAW e FCAW igual a 0,8 , determinou-se a energia de soldagem $(\mathrm{H})$ de $1,62 \mathrm{~kJ} . \mathrm{mm}-1$, a qual se buscou seguir em todos os testes, entretanto devido a questões operacionais houve oscilações em torno desse valor. Para os passes de raiz, ocorreram maiores discrepâncias, de forma que o soldador se limitou apenas às questões operacionais, buscando a obtenção de um perfil de cordão adequado (acabamento e penetração). Apesar disso, todos os procedimentos e passes se mantiveram dentro das recomendações dos fabricantes dos AID, os quais indicam a energia entre 0,5 e $2,5 \mathrm{~kJ} . \mathrm{mm}-1$ [8]. A Tabela 4 [8] apresenta os parâmetros reais e médios, dos passes de raiz e demais, respectivamente.

Os conjuntos soldados foram cortados transversalmente à direção de soldagem, para tornar possível a avaliação do metal de solda, da ZTA e do metal de base. A partir destes cortes, foram retirados corpos de prova de aproximadamente $5 \times 100 \times 10 \mathrm{~mm}$ e em duplicata, nas regiões de raiz e topo do conjunto soldado, como mostrado na Figura 1.

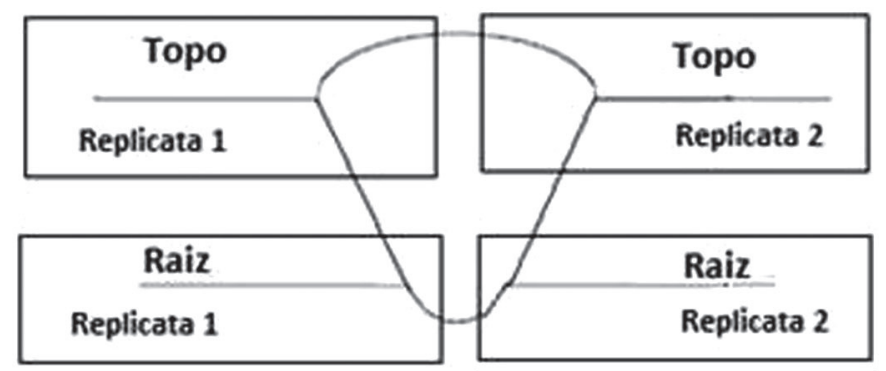

Figura 1. Local de remoção dos corpos de prova para os testes de corrosão

Para a realização dos ensaios eletroquímicos, os corpos de prova foram embutidos em resina baquelite. $\mathrm{O}$ contato elétrico necessário para os ensaios foi estabelecido soldando-se um fio de cobre na superfície da amostra antes do embutimento. As amostras foram lixadas utilizando-se lixas de carbeto de silício (SiC) com granulometria de 220, 400 e 600 e água como solução refrigerante. Imediatamente antes de cada análise, cada amostra foi lavada com água deionizada e etanol puro, desengraxada com acetona e seca com ar comprimido.

Os ensaios de polarização anódica potenciodinâmica foram realizados com o potenciostato PRINCETON Applied Research Versastat 3 e uma célula eletroquímica composta de um eletrodo de trabalho (material a ser estudado), um eletrodo de referência de $\mathrm{Ag} / \mathrm{AgCl}$ e um contra eletrodo ou eletrodo auxiliar de platina. Como eletrólito, foi utilizada uma solução neutra de $\mathrm{NaCl}$ $3,5 \% \mathrm{~m} / \mathrm{v}$ naturalmente aerada. Os ensaios foram realizados em duplicata, a uma taxa de varredura de $0,167 \mathrm{mV} / \mathrm{s}$, na faixa de potencial de $-200 \mathrm{mV}$ a $1,3 \mathrm{~V}$ em relação ao potencial de corrosão $\left({ }^{*} \mathrm{E}\right)$, determinado a partir do potencial de circuito aberto medido após 3 horas de imersão da amostra no eletrólito. Foram avaliadas simultaneamente, no ensaio de corrosão, todas as regiões da solda incluindo o MB (metal base). As amostras foram denominadas citando-se, nesta sequencia, o processo de soldagem (SMAW, GMAW ou FCAW), o consumível utilizado (2209 ou 2307), região da raiz (R) ou topo (T) e o número da réplica ( 1 ou 2). O potencial de pite foi determinado pela interseção das retas tangentes à região passiva e à região transpassiva, de acordo com a literatura [9].

Após o término do ensaio de polarização, as amostras foram lavadas e secas para posterior análise micrográfica. A área submetida ao ensaio de polarização, para cada réplica de teste, foi determinada usando-se o software analisador de imagens “AnalySIS DOCU 5.0 - Soft Imaging System GmbH”. Depois do ensaio de polarização, as amostras foram submetidas à análise microscópica para avaliação da morfologia e da região de ocorrência dos pites. Para análise por microscopia óptica, a amostra foi fotografada com auxílio do microscópio óptico Olympus BX60. A captação das imagens foi feita utilizandose uma câmera Evolution LC Color - PLA662 integrada ao software computacional de captação e edição de imagens "AnalySIS DOCU 5.0 - Soft Imaging System GmbH".

\section{Resultados e Discussão}

Foram obtidas curvas de polarização potenciodinâmica para as amostras soldadas pelo processo SMAW (Figura 2), GMAW (Figura 3) e FCAW (Figura 4). Foi selecionada uma réplica representativa de cada condição para apresentação.

A região da raiz da junta soldada pelo processo SMAW com consumível 2307 apresentou uma região de passivação primária com densidade de corrente de passivação similar à da região passiva da junta soldada com o consumível 2209. Apresentou, ainda, uma região de passivação secundária com uma maior densidade de corrente de passivação. No caso da região de topo, a região soldada com o consumível 2209 apresentou uma maior região passiva associada a uma menor densidade de corrente de passivação em relação à região de topo soldada pelo processo SMAW com o consumível 2307.

Apenas a amostra FCAW2307R-1 apresentou uma região de passivação definida, com posterior variação brusca da corrente no potencial de transpassivação ou de pite. As amostras FCAW2307R-2, FCAW2209R-1, FCAW2209R-2, FCAW2307T-1 e FCAW2307T-2 não apresentaram o comportamento passivo esperado e potencial de pite definido. Nestas amostras, o comportamento foi característico do processo de corrosão generalizada; a densidade de corrente anódica aumenta continuamente com o potencial até a corrente se estabilizar, com a evolução de oxigênio e oxidação da água.

As amostras soldadas pelo processo GMAW apresentaram regiões de passivação maiores (Figura 3), com maior potencial de pite e menores valores de densidade de corrente de passivação, mostrando-se o processo de soldagem que menos afetou a resistência à corrosão por pite do aço lean duplex UNS S32304 em meio de solução aquosa de cloreto de sódio. A utilização de materiais dissimilares gera a formação de micropilhas galvânicas e de ação local. Entretanto, foi observado que, para um mesmo conjunto metal base/consumível, as juntas soldadas pelo processo GMAW apresentaram maior resistência à corrosão localizada em meio salino.

A Figura 5 apresenta os valores do potencial de pite em função do processo de soldagem utilizado, do consumível usado e da região analisada (raiz e topo). 


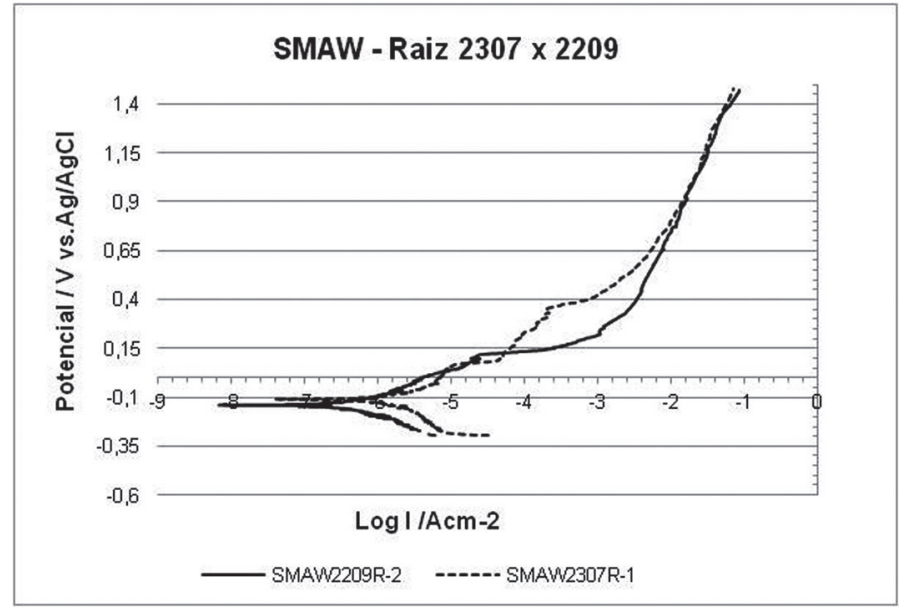

A)

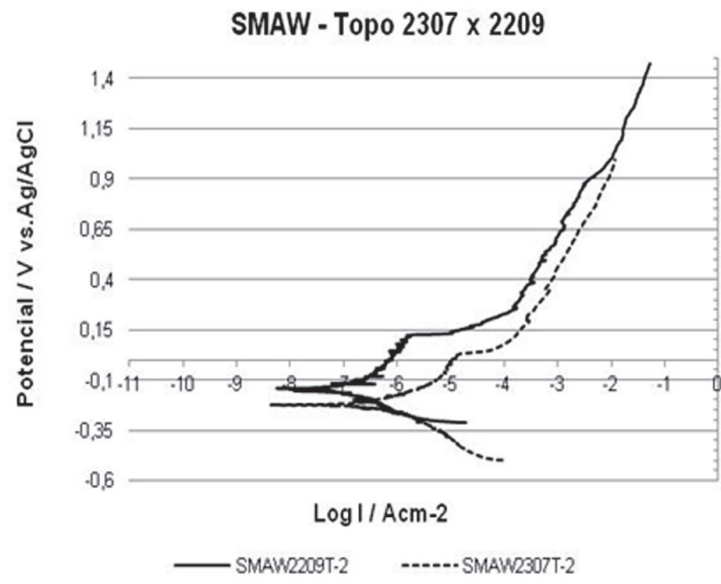

B)

Figura 2. Curvas de polarização obtidas para as juntas soldadas pelo processo SMAW na região da raiz (A) e topo (B)

GMAW - Raiz 2307 x 2209

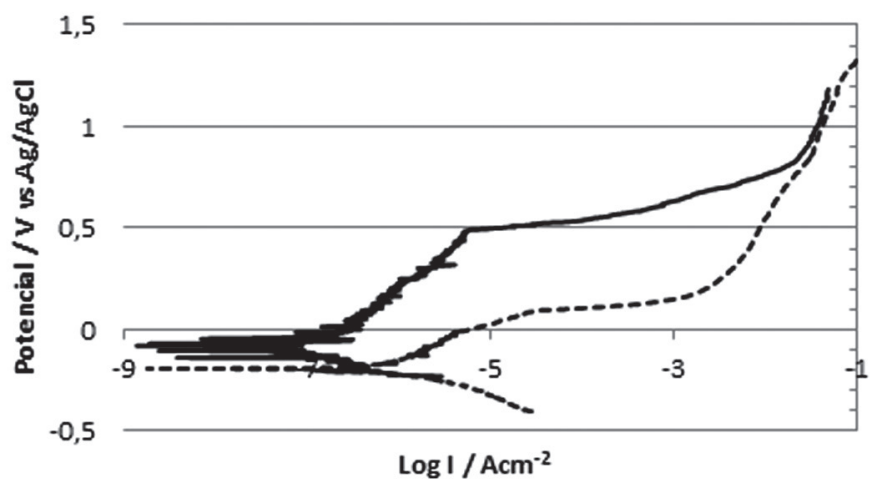

-----GMAW2307R-2 - GMAW2209R-1

A)
GMAW - Topo 2307 x 2209

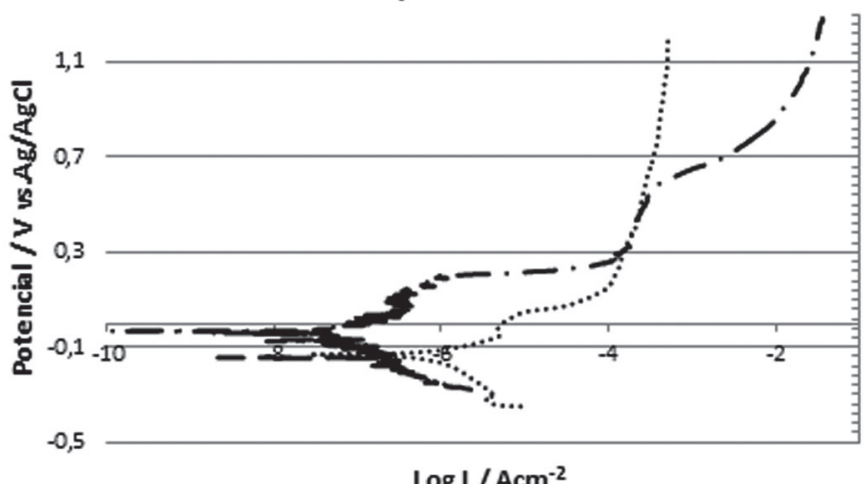

GMAW2307T-1 - - GMAW2209T-2

B)

Figura 3. Curvas de polarização obtidas para as juntas soldadas pelo processo GMAW na região da raiz (A) e topo (B)

FCAW - Raiz 2307 x 2209

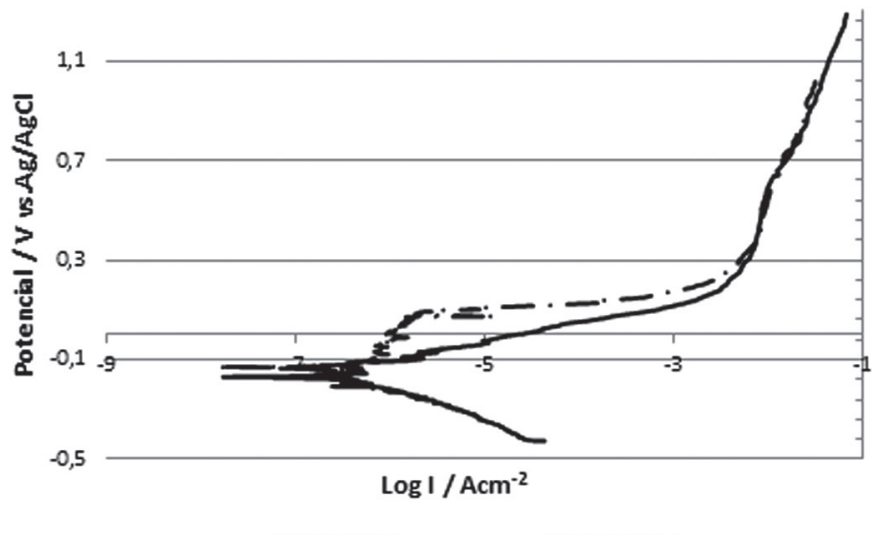

- - FCAW2307R-1 - FCAW2209R-1

A)
FCAW - Topo 2307 x 2209

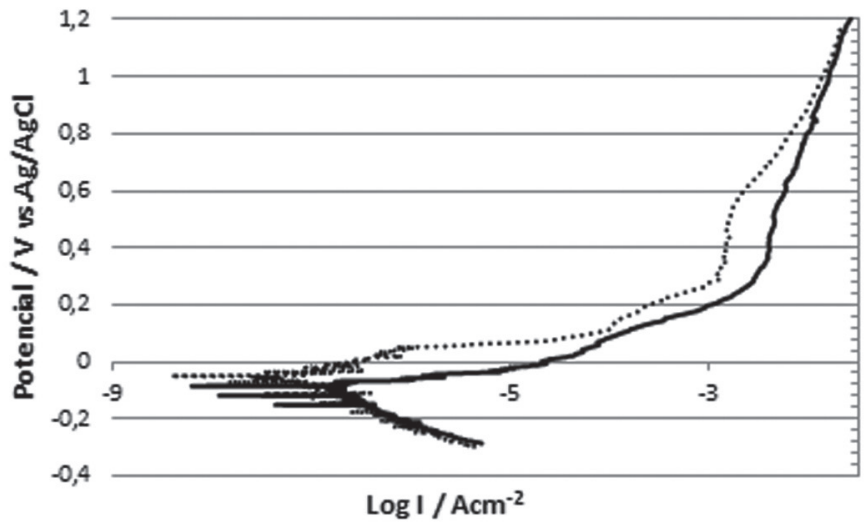

FCAW2307T-1 FCAW2307T-2

B)

Figura 4. Curvas de polarização obtidas para as juntas soldadas pelo processo FCAW na região da raiz (A) e topo (B) 


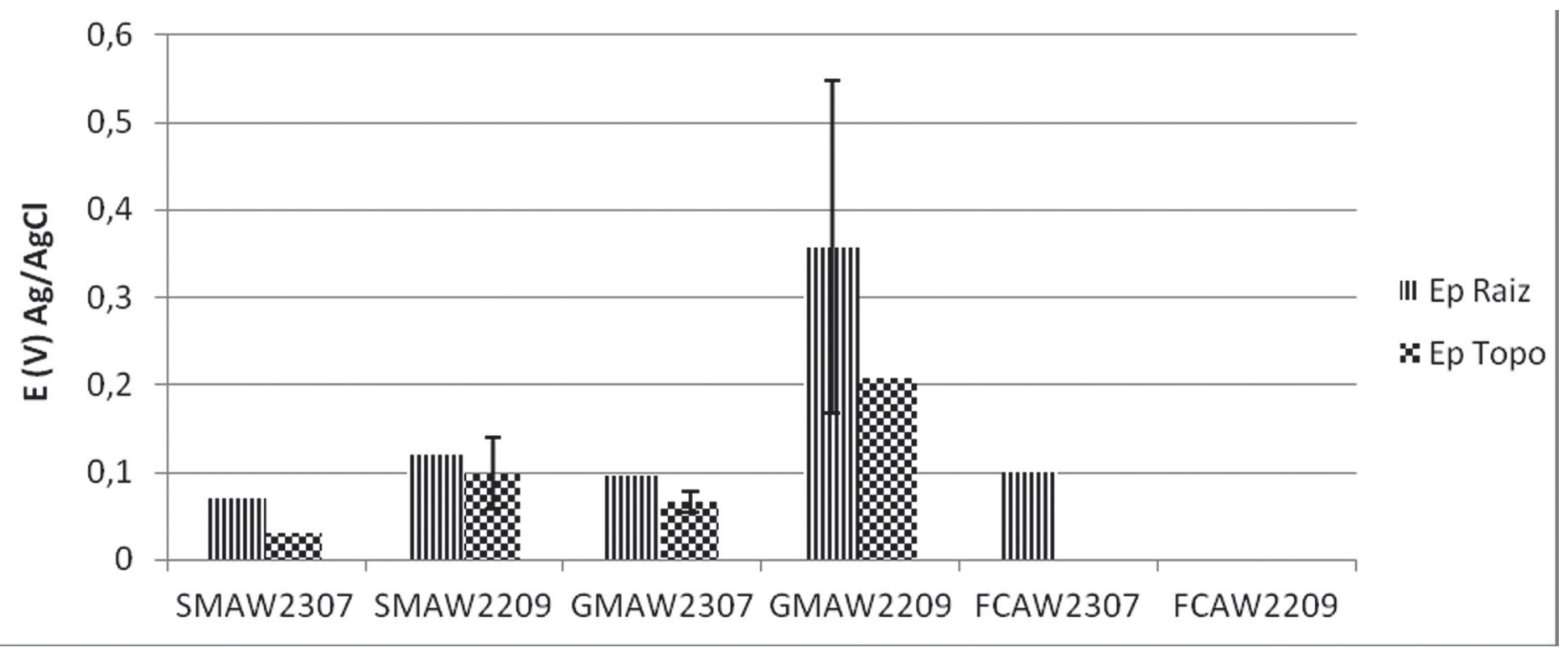

Figura 5. Valores do potencial de pite das juntas soldadas

Quanto ao potencial de pite (Ep), observou-se para os processos SMAW e GMAW que as amostras da região da raiz apresentaram maior potencial de pite que as de topo. De acordo com Cardoso Junior et al. [8], foi usada maior energia de soldagem para os passes de raiz em função de questões operacionais e esse aumento de energia resultou numa maior proporção de austenita na ZTA da raiz em relação ao topo, o que contribuiu para o melhor comportamento frente à corrosão da região da raiz em relação à região do topo. Uma energia de soldagem alta leva a uma velocidade de resfriamento menor e, consequentemente, ao favorecimento da formação de austenita e do adequado balanceamento químico entre as fases, tanto na zona fundida como na ZTA, levando a uma maior resistência à corrosão localizada. Entretanto, a energia de soldagem não deve ser excessivamente alta, a qual poderia ocasionar a formação de fases deletérias, as quais são prejudiciais tanto para a resistência a corrosão quanto para as propriedades mecânicas.

As amostras soldadas com o consumível 2209 apresentaram maior potencial de pite que as soldadas com o consumível 2307. É importante ressaltar que o consumível 2209 apresenta maior valor de $\mathrm{PRE}_{\mathrm{N}}$ do que o consumível 2307, devendo apresentar melhor comportamento frente à corrosão no meio estudado. $\mathrm{O}$ consumível 2209 apresenta como diferencial maiores teores de Ni e Mo em relação ao consumível 2307 e ao aço 2304 solubilizado. O efeito benéfico da adição de Mo aos aços inoxidáveis em sua resistência à corrosão foi atribuído à presença das espécies $\mathrm{Mo}^{6+}$ no filme passivo, tornando-o mais estável contra a ruptura causada pelos íons cloretos, e à formação de compostos de Mo insolúveis no meio agressivo próximo ao pite, facilitando a repassivação [10]. Um aumento do teor de níquel na liga contribui para o aumento da resistência à corrosão uniforme e por pite [11]. Entretanto, tais elementos contribuem para um aumento do $\mathrm{PRE}_{\mathrm{N}}$ apenas na $\mathrm{ZF}$, não impactando na resistência à corrosão localizada da ZTA, que foi a região preferencialmente atingida. A literatura relata um pior comportamento frente à corrosão da zona termicamente afetada em relação às demais

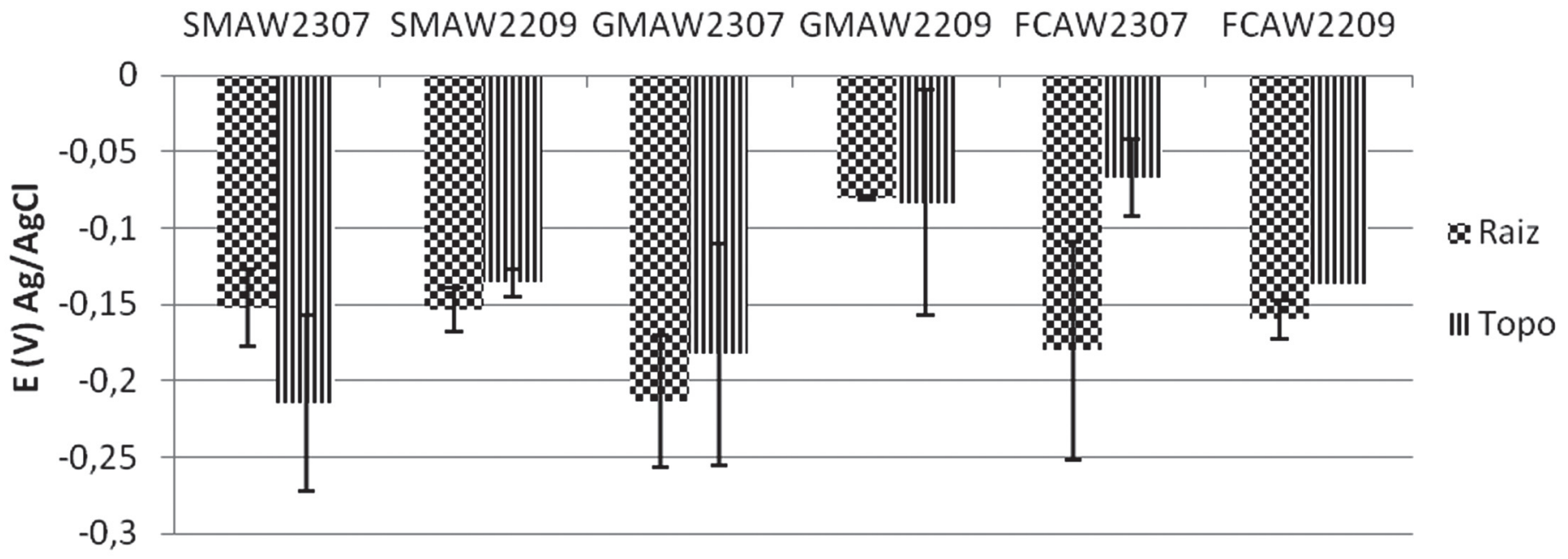

Figura 6. Potencial de corrosão das amostras de aço lean duplex soldadas pelos processos SMAW, GMAW e FCAW 
regiões em aços austeníticos soldados [12]. Segundo Cardoso Junior et al [8] não houve nenhuma tendência de maior ou menor austenitização em função da composição química do metal de solda $(23 \% \mathrm{Cr} 7 \% \mathrm{Ni}$ ou $22 \% \mathrm{Cr} 9 \% \mathrm{Ni})$; isto ocorreu em virtude de que o consumível 2209 tem maior teor de Mo e Ni e menor teor de Cr se comparado com o consumível 2307. Ou seja, os elementos austenitizantes e ferritizantes foram balanceados,

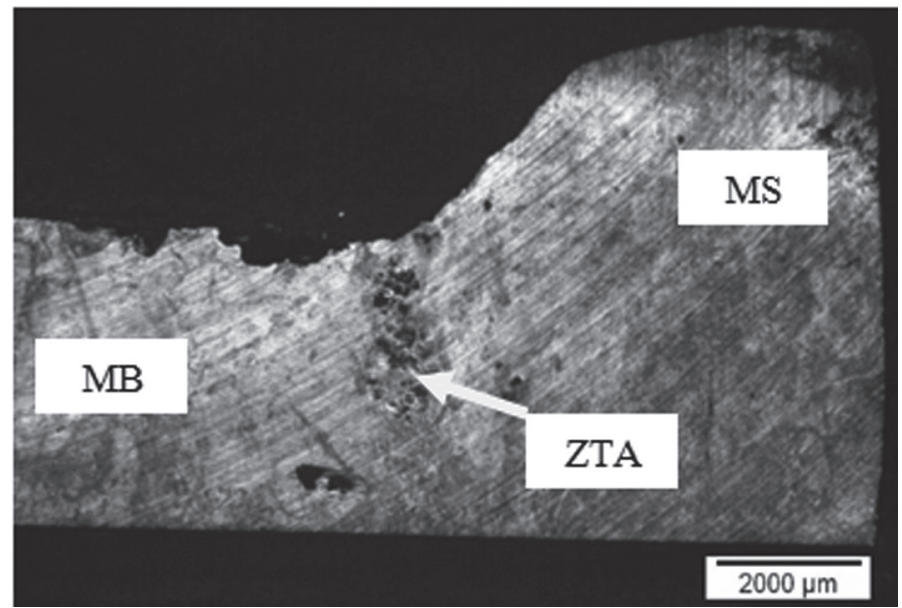

(a) SMAW 2307R-1

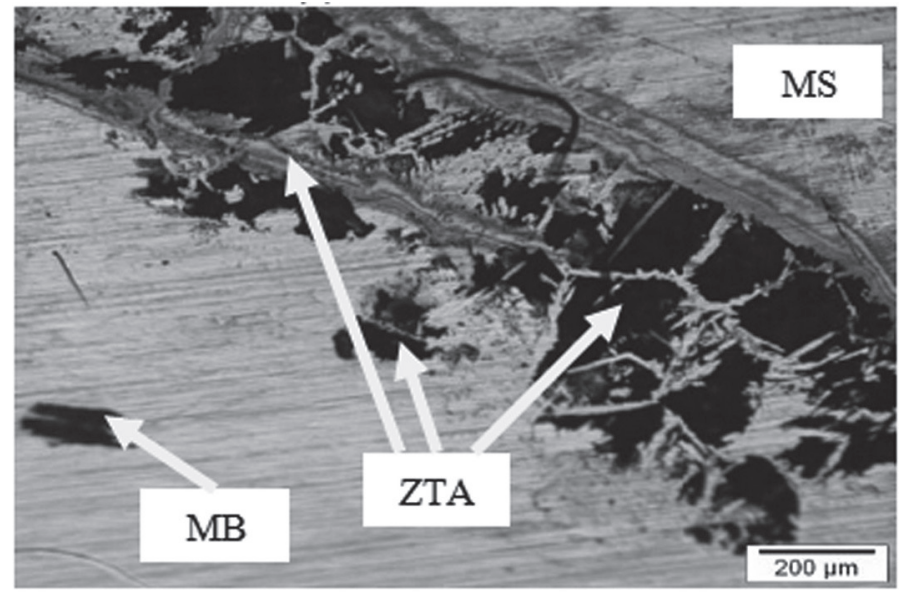

(c) SMAW2209R-1 / ZTA

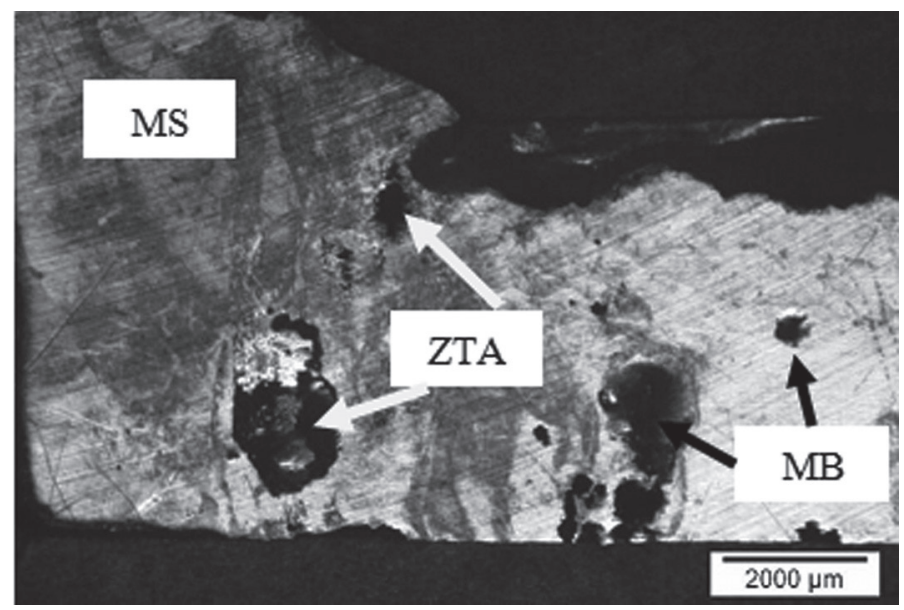

(e) SMAW2209T-2 / ZF e ZTA não afetando na proporção de fases, porém afetando o PREN, não devendo ser a fração de austenita o parâmetro responsável pelo melhor comportamento frente à corrosão das amostras que utilizaram o consumível 2209.

As amostras soldadas com a condição GMAW2209 apresentaram os maiores valores de potencial de pite e, portanto, a maior resistência à corrosão localizada no meio de cloreto de

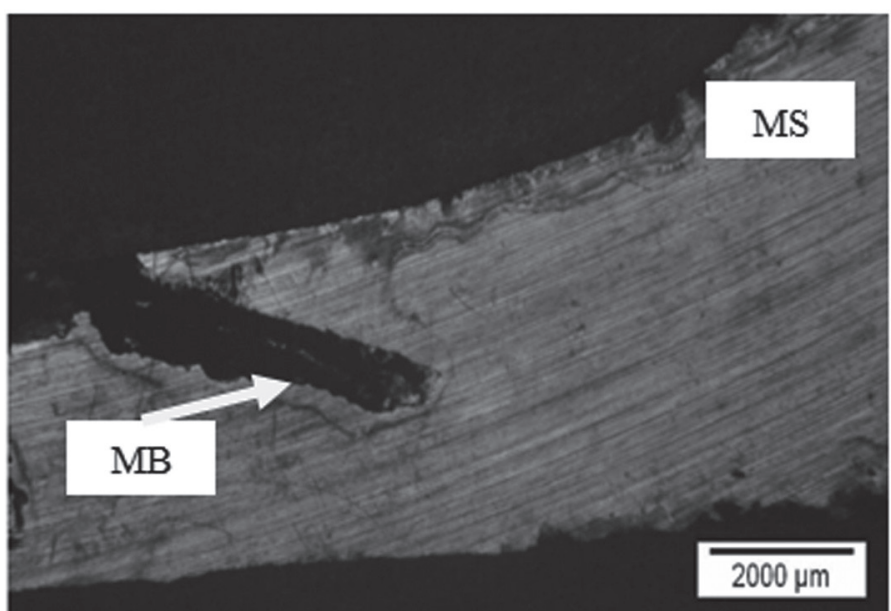

(b) SMAW2307R-2 / MB

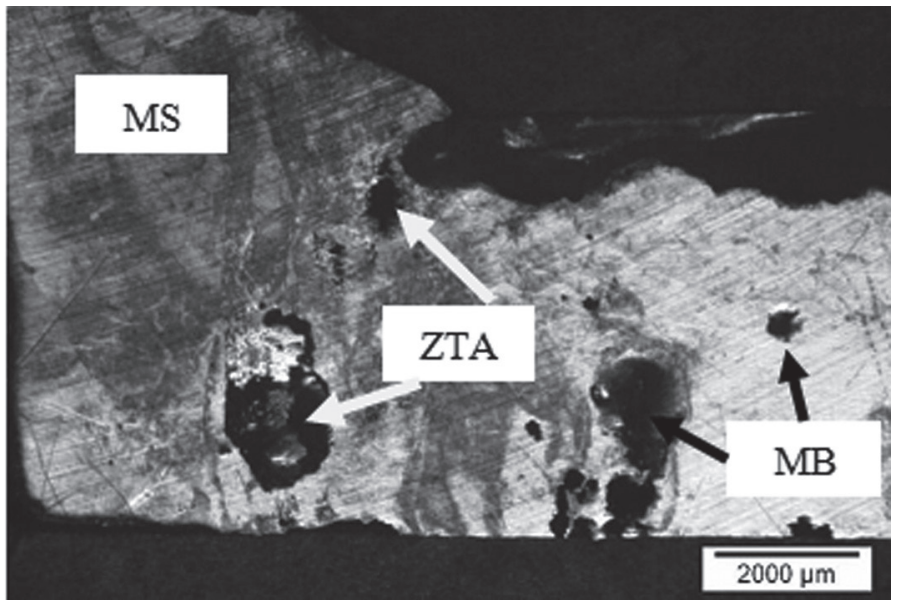

(d) SMAW2209R-3 / ZF e ZTA

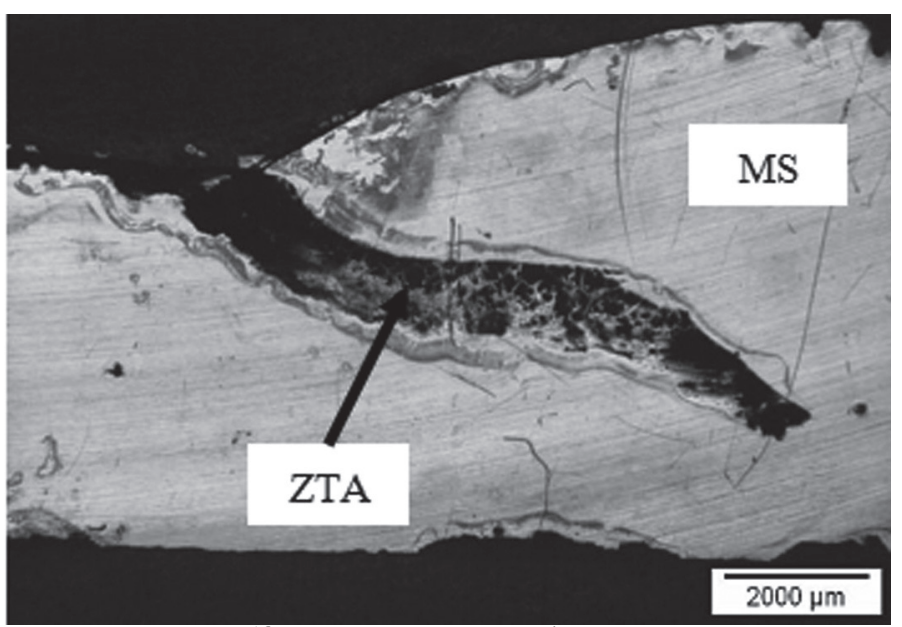

(f) SMAW2307T-2 / ZTA

Figura 7. Micrografias obtidas por microscopia ótica das juntas de aço lean duplex soldadas pelo processo SMAW 
sódio aquoso, dentre todas as amostras testadas. A Figura 6 apresenta os valores do potencial de corrosão das amostras de aço lean duplex soldadas. As amostras soldadas usando-se o processo GMAW e o consumível 2209 apresentaram o maior potencial de corrosão, sendo as amostras mais nobres dentre as analisadas. Cardoso Junior et al. [8] encontraram percentuais estatisticamente similares de austenita na ZTA das amostras soldadas pelos processos SMAW, GMAW e FCAW, não sendo este, portanto, um fator determinante para o comportamento superior das amostras GMAW2209. O diferencial apresentado pelo processo GMAW é a utilização de gás de proteção com

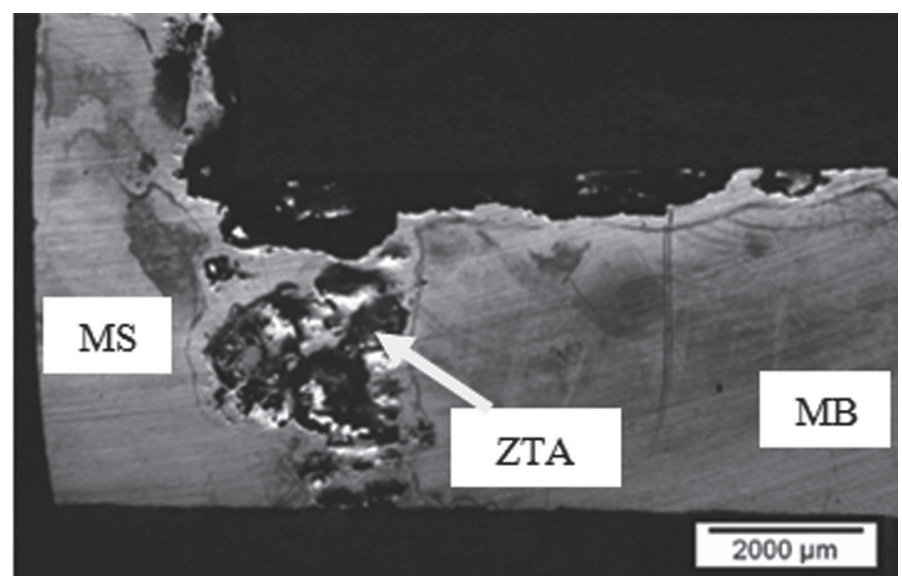

(a) GMAW2307R-1

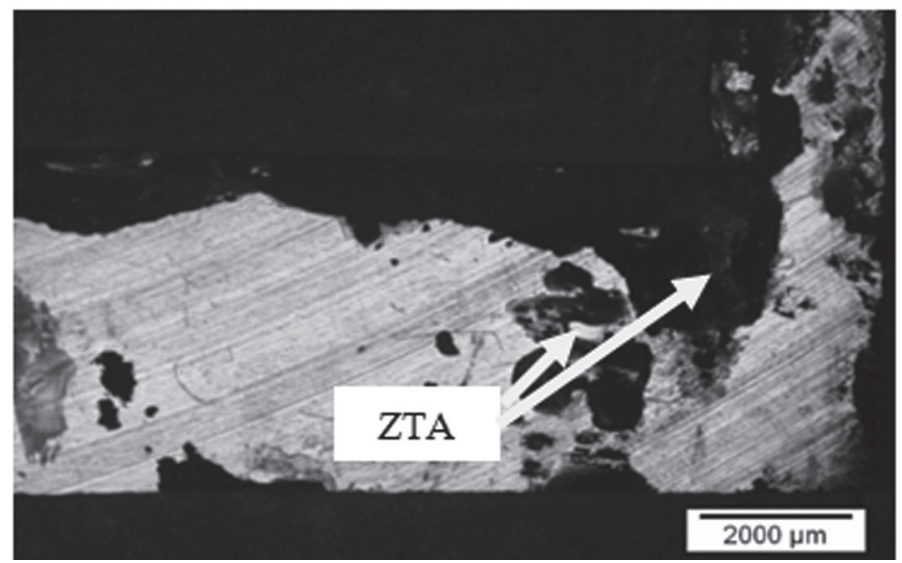

(c) GMAW2307R-2

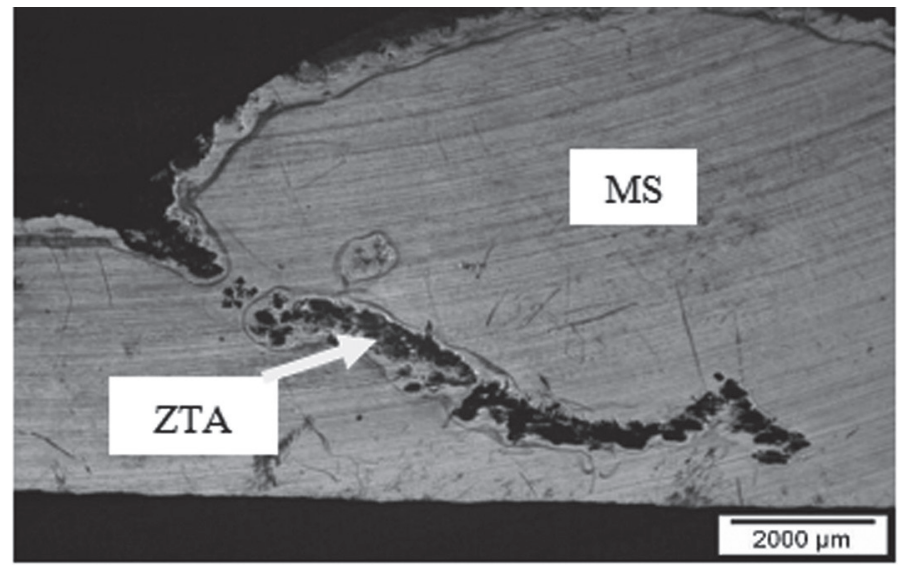

(e) GMAW2307T-3 adição de $\mathrm{N}_{2}$, que aumenta o teor final de nitrogênio na $\mathrm{ZF}$, garantindo uma maior fração volumétrica de austenita nesta região, além de alto PRE. Segundo Cardoso Junior et al. [8] tal adição beneficiou realmente a formação de austenita na ZF das amostras soldadas com o processo GMAW, mas o efeito não foi significativo para a ZTA. Portanto, a maior resistência à corrosão apresentada pela ZTA das amostras soldadas pelo processo GMAW não pode ser diretamente relacionada à adição de $\mathrm{N}_{2}$ ao gás de proteção.

As Figuras 7, 8 e 9 apresentam algumas das imagens obtidas das juntas soldadas pelos processos SMAW, GMAW e FCAW,

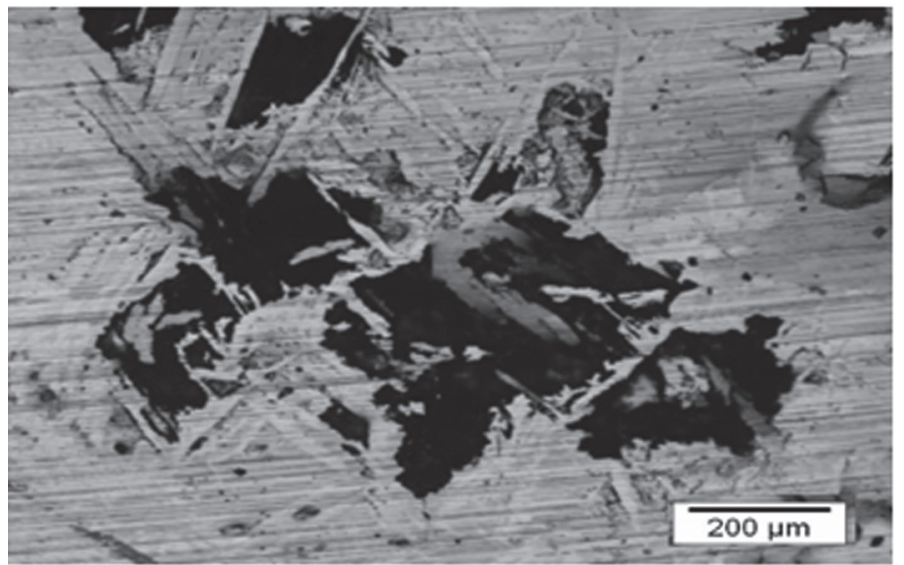

(b) GMAW2307R-1 / ZTA

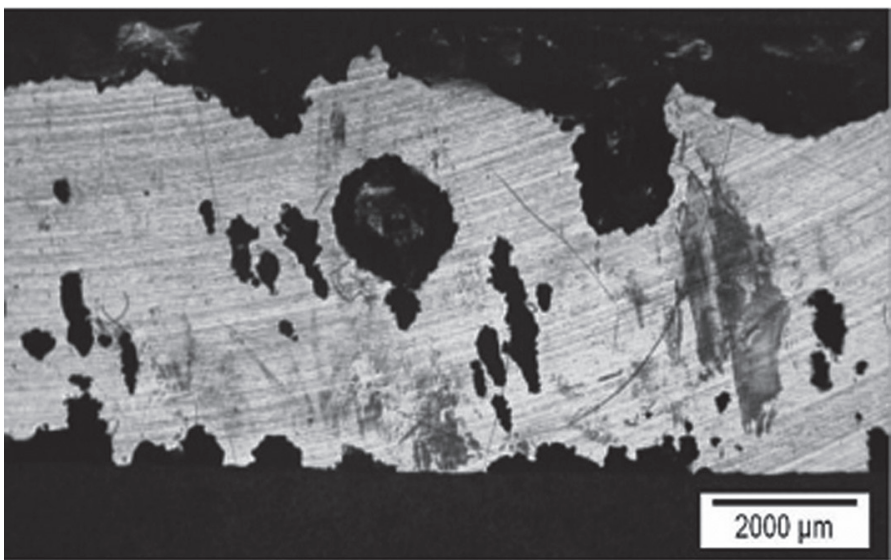

(d) GMAW2307R-2 / MB

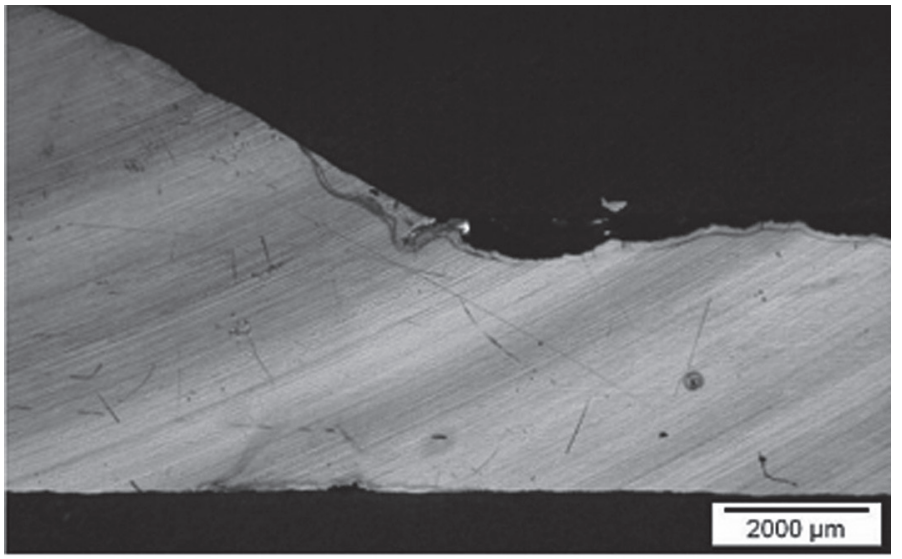

(f) GMAW2209T-1 / ZF e ZTA

Figura 8. Micrografias obtidas por microscopia ótica das juntas de aço lean duplex soldadas pelo processo GMAW 


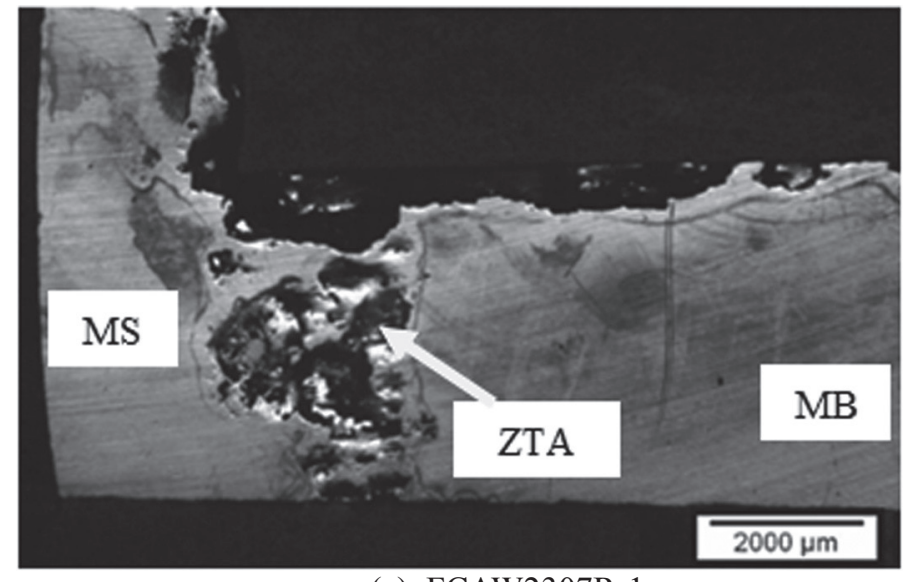

(a) FCAW2307R-1

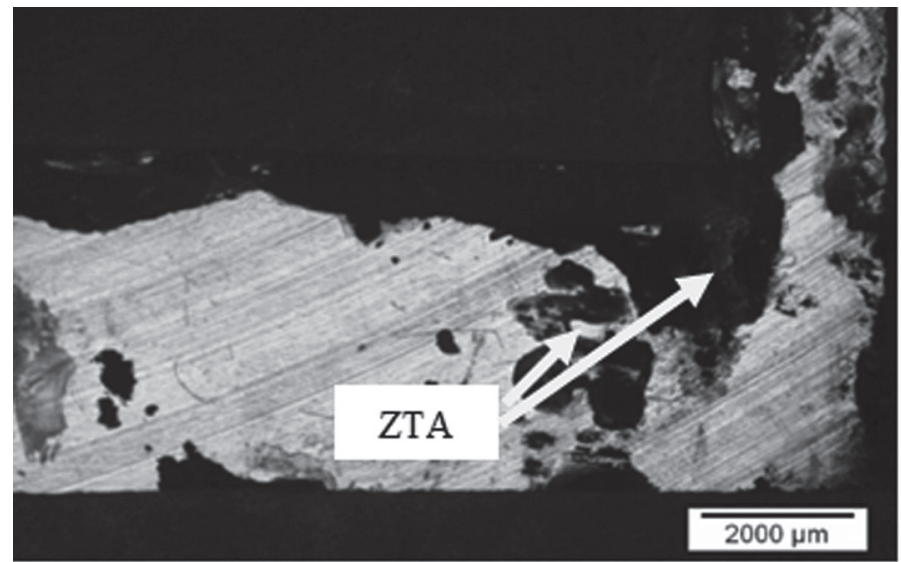

(c) FCAW2307R-2 / ZF e ZTA

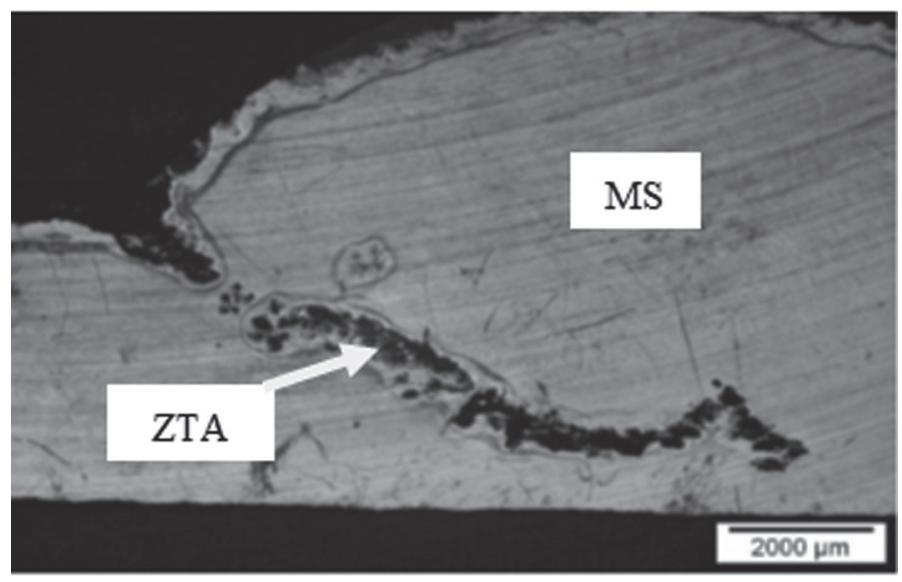

(e) FCAW2209T-1 / ZTA e MB

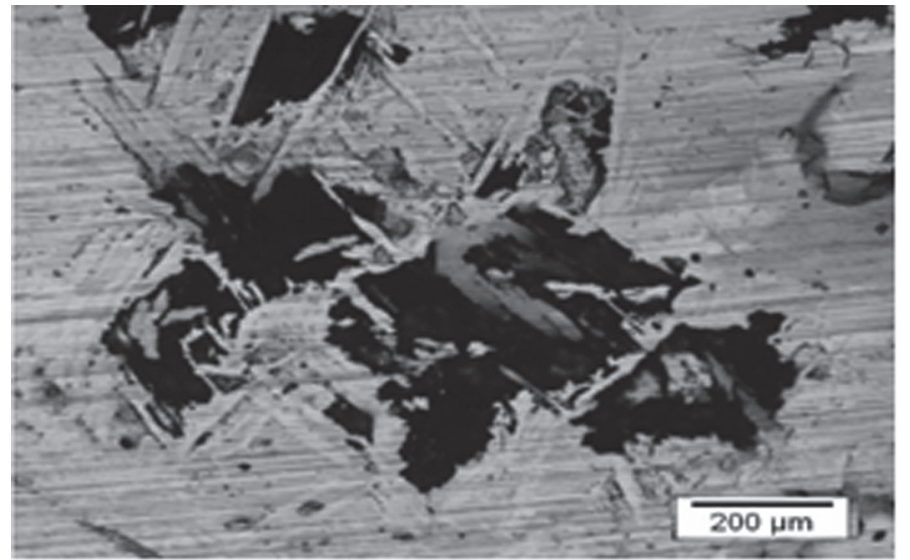

(b) FCAW2307R-1 / ZTA

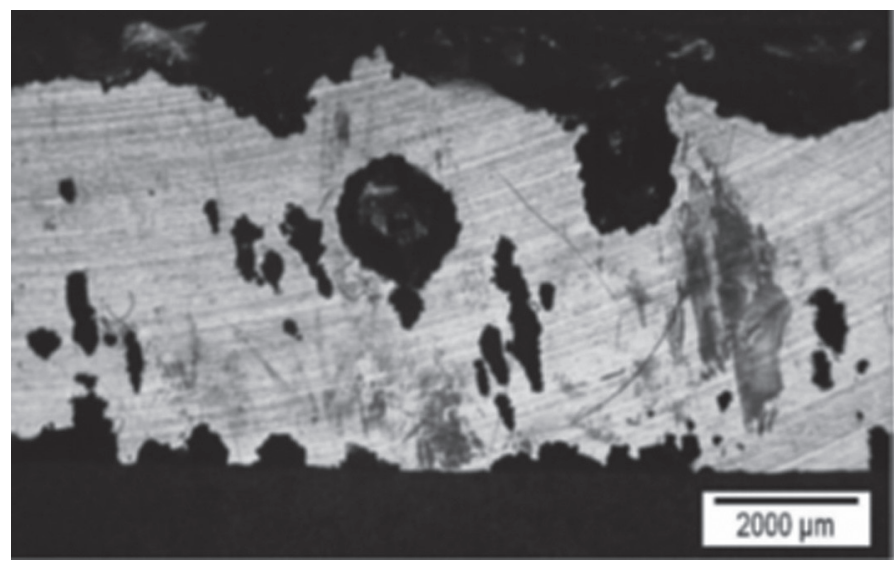

(d) FCAW2209R-1/ MB

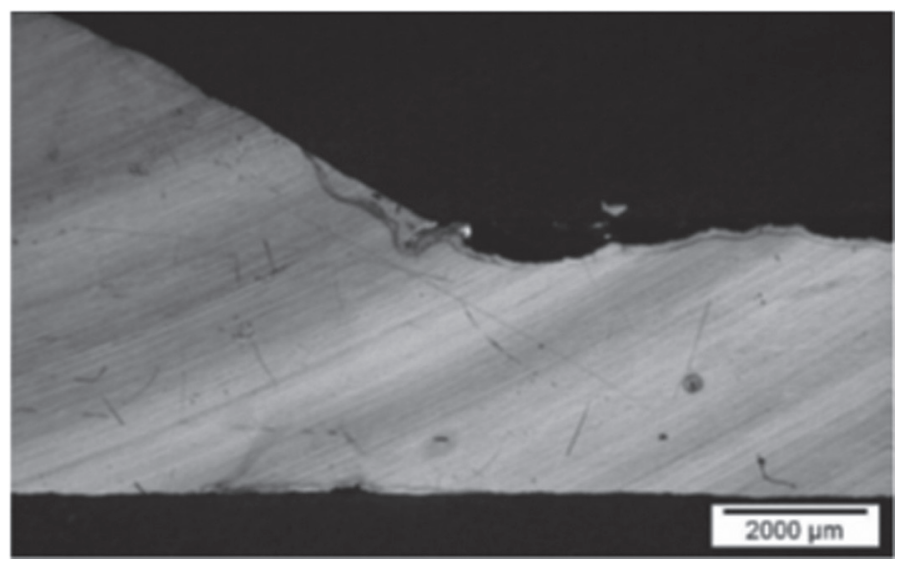

(f) FCAW2307T-2 / ZTA e MB

Figura 9. Micrografias obtidas por microscopia ótica das juntas de aço lean duplex soldadas pelo processo FCAW

com o consumível 2307, na região da raiz.

As micrografias revelam ataque corrosivo em todas as amostras avaliadas, mesmo naquelas que não apresentaram potencial de pite definido. Para a maioria das amostras (SMAW2307R-1, SMAW2209R-1, SMAW2307T-2, SMAW2307T-3 e SMAW2209T-2) a corrosão aconteceu de forma localizada na ZTA. Para essas amostras percebeu-se claramente que o ataque aconteceu de forma seletiva na fase ferrita, conforme observado na Figura 7(c), onde a fase ferrita sofreu corrosão, restando apenas austenita. Jiang et al [13] relatam que, após testes de temperatura crítica de pite de juntas soldadas de aço duplex 2304, a análise morfológica mostrou o ataque seletivo à fase ferrítica em todas as amostras testadas. $\mathrm{O}$ ataque seletivo à fase ferrítica foi constatado em trabalho prévio de um dos autores [14]. Para as amostras SMAW2209R-3, SMAW2307T-1 e SMAW2209T-1 aconteceram ataques de corrosão distribuídos pelo metal base (MB). A amostra SMAW2307R-2 apresentou comportamento isolado com ataque corrosivo seletivo concentrado no MB. Observou-se, ainda, que a ZF permaneceu livre de corrosão para todas as amostras de aço 
lean duplex soldadas pelo processo SMAW.

As micrografias revelam ataque corrosivo para a maioria das amostras avaliadas, mesmo para aquelas que não apresentaram potencial de pite definido. Para a maioria das amostras (GMAW2307R-1, GMAW2307R-3, GMAW2307T-3 e GMAW2209T-2) a corrosão aconteceu de forma localizada na ZTA, com ataque seletivo da fase ferrita. Para as amostras GMAW2307R-2 e GMAW2209R-2, aconteceram ataques de corrosão distribuídos pelo MB. Este fato indica que o MS é mais resistente à corrosão que o MB. Já as amostras GMAW2307T-1 e GMAW2209T-1 não apresentaram ataque corrosivo significativo. Observou-se também, ao contrário do ocorrido no processo SMAW, que a zona fundida de algumas das amostras apresentou ataque localizado de corrosão.

Para as amostras FCAW2307R-1, FCAW2307R-2 e FCAW2307T-2, a corrosão aconteceu de forma localizada na ZTA, com características de corrosão seletiva da fase ferrita [14]. A literatura relata a associação do decréscimo do teor de ferrita em juntas soldadas de aço duplex 2304 com o aumento da resistência à corrosão localizada, avaliada pela temperatura crítica de pite [13,15]. Para as amostras FCAW2209R-1, FCAW2307T-1 e FCAW22209T-2 aconteceram ataques localizados de corrosão tanto na ZTA quanto no MB. Já as amostras FCAW2209R-2 e FCAW2209T-1 não apresentaram ataque corrosivo significativo, evidenciando a possibilidade de corrosão generalizada. Observou-se, também, assim como ocorrido no processo SMAW, que a zona fundida das amostras permaneceu livre de ataques localizados.

As micrografias, de uma maneira geral, revelaram que as amostras soldadas pelo processo FCAW apresentaram-se menos atacadas que as soldadas pelos processos SMAW e GMAW, principalmente pela forma de ataque generalizado em toda a superfície, não apresentando pites, característicos de corrosão localizada.

\section{Conclusões}

Através desse trabalho foi possível concluir que:

1. As juntas soldadas pelo processo GMAW, com o consumível 2209, apresentaram a maior resistência à corrosão por pite em solução aquosa de cloreto de sódio, apresentando os maiores valores de potencial de pite e de corrosão, e as menores densidades de corrente de passivação.

2. As juntas de aço lean duplex soldadas pelo processo FCAW apresentaram característica de corrosão generalizada, sendo que a maioria das amostras não apresentou um potencial de pite definido.

\section{Agradecimentos}

A Aperam South America pelo Fornecimento do aço e suporte, a ESAB Indústria e Comércio LTDA pelo fornecimento dos consumíveis e ao LRSS-UFMG pelo fornecimento da infraestrutura para execução da soldagem e análises.

\section{Referências Bibliográficas}

[1]WESTIN, E.M.Microstructure and properties of welds in the lean duplex stainless steel LDX 2101®: 2010. Doctoral Thesis in Materials Science. Stochholm, Sweden.

[2] ZHANG, L. et al., Effect of aging on the corrosion resistance of 2101 lean duplex stainless steel, Materials Characterization, v. 60, n. 12, p. 1522-1528, Dez. 2009.

[3] T.J. MESQUITA, T.J. et al., Lean duplex stainless steelsThe role of molybdenum in pitting corrosion of concrete reinforcement studied with industrial and laboratory castings Materials Chemistry and Physics, v. 132, In. 2-3, p. 967-972, Fev. 2012.

[4] XU, J. et al., Potentiostatic Electrochemical Noise Analysis of 2101 Lean Duplex Stainless Steel in $1 \mathrm{~mol} / \mathrm{L} \mathrm{NaCl}$, Journal of Materials Science \& Technology, v. 28, n. 5, p. 474-480, Maio 2012.

[5] FREDRIKSSON, W.; EDSTRÖM, K.; OLSSON, C.-O.A., XPS analysis of manganese in stainless steel passive films on 1.4432 and the lean duplex 1.4162, Corrosion Science, v. 52, n. 7, p. 2505-2510, Jul. 2010.

[6] VIGNAL, V. et al., Passive properties of lean duplex stainless steels after long-term ageing in air studied using EBSD, AES, XPS and local electrochemical impedance spectroscopy, Corrosion Science, v. 67, p.109-117, Fev. 2013.

[7] WESTIN, E.M.; OLSSON, C.-O.A.; HERTZMAN, S.; Weld oxide formation on lean duplex stainless steel, Corrosion Science, v. 50, n. 9, p. 2620-2634, Set.2008.

[8] CARDOSO JUNIOR, R. et al., Avaliação da soldagem multipasse de chapas espessas de aços inoxidáveis lean duplex UNS S32304 soldadas pelos processos SMAW, GMAW e FCAW: parte 1: propriedades mecânicas. Soldagem e Inspeção (Impresso), v. 17, p. 306-316, 2012.

[9] DO NASCIMENTO, A.M. et al., Pitting Corrosion Resistance of Cast Duplex Stainless Steels in 3.5\% NaCl Solution. Materials Characterization, v. 59, p. 1736-1740, 2008.

[10] PARDO, A. et al., Pitting corrosion behaviour of austenitic stainless steels - combining effects of Mn and Mo additions, Corrosion Science, v. 50, n. 6, p. 1796-1806, Jun. 2008.

[11] POTGIETER, J.H. et al, Influence of nickel additions on the corrosion behaviour of low nitrogen $22 \% \mathrm{Cr}$ series duplex stainless steels, Corrosion Science, v. 50, n. 9, p. 2572-2579, Set. 2008.

[12] SÁNCHEZ-TOVAR, R.; MONTAÑÉS, M.T.; GARCÍAANTÓN, J., Effect of the micro-plasma arc welding technique on the microstructure and pitting corrosion of AISI 316L stainless steels in heavy LiBr brines, Corrosion Science, v. 53, n. 8, p. 2598-2610, Agosto 2011.

[13] CHEN et al, Influence of cooling rate on microstructure evolution and pitting corrosion resistance in the simulated heataffected zone of 2304 duplex stainless steels, Corrosion Science, v. 58, p.168-174, Maio 2012.

[14] CARDOSO JUNIOR, R. Avaliação da soldagem multipasse de chapas espessas do aço inoxidável Lean Duplex UNS S32304 soldadas pelos processos SMAW, GMAW e FCAW: 2012. 106 p. Dissertação (Mestrado) - Escola de Engenharia, Universidade Federal de Minas Gerais, Belo Horizonte. 
[15] TAN, H.; WANG, Z.; JIANG, Y.; YANG, Y.; DENg, B.; SONG, H.; LI, J., Influence of welding thermal cycles on microstructure and pitting corrosion resistance of 2304 duplex stainless steels, Corrosion Science, v. 55, p. 368-377, Fev. 2012. 